\title{
Validity of Cone-beam Computed Tomography in Assessment of Morphological Bony Changes of Temporomandibular Joints
}

\author{
Hala M Abdel-Alim ${ }^{1}$, Zeinab Abdel-Salam², Soliman Ouda ${ }^{3}$, Fatima M Jadu ${ }^{4}$, Ahmed M Jan ${ }^{5}$
}

\begin{abstract}
Aim: The aim of the current study was to correlate the clinical symptoms that are associated with temporomandibular disorder (TMD) to the osseous changes occurring in the affected temporomandibular joint (TMJ), as detected by cone-beam computed tomography (CBCT).

Materials and methods: The clinical data of patients that presented with TMJ symptoms was collected and correlated with the CBCT findings for the same patients. Patient recruitment took place over a 1-year period in the Oral and Maxillofacial Surgery and Oral and Maxillofacial Radiology department of the same academic institution.

Results: There was a limited mouth opening $(\mathrm{MO})(<3 \mathrm{~cm})$. More importantly, there was a statistically significant positive relation between pain and loss of cortication.

Conclusion: There was no significant correlation between CBCT findings consistent with TMJ degeneration and clinical symptoms.

Clinical significance: Cone-beam computed tomography evaluation of the TMJ is important for providing information about the state and level of TMJ degeneration if any. However, clinical findings should be the most important factor when considering management options for symptomatic TMJ.

Keywords: Cone-beam computed tomography, Degeneration, Temporomandibular disorder, Temporomandibular joint.

The Journal of Contemporary Dental Practice (2020): 10.5005/jp-journals-10024-2732
\end{abstract}

\section{INTRODUCTION}

Temporomandibular joint (TMJ) is a highly specialized functional joint. It is unique because both joints work together in coordination as a single unit. It is formed by an articulation between the mandibular condyle and the mandibular fossa of the temporal bone. The joints are assisted by muscles and tendons, which all together perform a wide range of movements such as opening and closing by depressing, elevating, and protruding the mandible as well as side to side movements. ${ }^{1}$

Impairments within the joints are presented as dysfunction of the TMJ, known as temporomandibular disorder (TMD). This is usually associated with clinical symptoms such as pain, clicking, and limited mouth opening (MO). Temporomandibular disorder and its associated symptoms significantly affect the quality of life and constitute a disability that affects the socioeconomic status of inflicted individuals because of absences from work and the burden of treatment costs. ${ }^{2,3}$

The pathogenesis of TMD is believed to be chronic irritation to the jaw muscles that results in chronic spasm, which affects their blood supply and leads to hypoxia of these muscles. This functional disharmony results in chronic irritation of the meniscus within the TMJ leading to its dehydration and displacement with abnormal joint movement and eventual damage with associated inflammation and pain. ${ }^{4}$ Milam et al. attributed TMD to mechanical disturbances causing an imbalance between catabolic and anabolic processes that results in progressive degradation of the cartilage, which leads to inflammation; this inflammation can be relieved by splint therapy and intra-articular arthrocentesis. ${ }^{5}$ Osteoarthritis, however, is an age-related joint disorder that is characterized by advanced destruction of the articular surfaces and further erosion and loss of the subchondral cortical layer in response to repetitive overload. ${ }^{5,6}$

Diagnosing TMD requires a thorough medical and socioeconomic history, comprehensive clinical examination,
1,5 Department of Oral and Maxillofacial Surgery, Faculty of Dentistry,
King Abdulaziz University, Jeddah, Kingdom of Saudi Arabia
${ }^{2-4}$ Department of Oral Diagnostic Sciences, Faculty of Dentistry, King
Abdulaziz University, Jeddah, Kingdom of Saudi Arabia

Corresponding Author: Fatima M Jadu, Department of Oral Diagnostic Sciences, Faculty of Dentistry, King Abdulaziz University, Jeddah, Kingdom of Saudi Arabia, Phone: +966-254-0000, e-mail: fjadu@kau. edu.sa

How to cite this article: Abdel-Alim HM, Abdel-Salam Z, Ouda S, et al. Validity of Cone-beam Computed Tomography in Assessment of Morphological Bony Changes of Temporomandibular Joints. J Contemp Dent Pract 2020;21(2):133-139.

Source of support: This project was funded by the Deanship of Scientific Research (DSR) at King Abdulaziz University, Jeddah, under grant no. (G-496-165-39). The authors, therefore, acknowledge with the thanks DSR for technical and financial support.

Conflict of interest: None

and diagnostic imaging in most cases. ${ }^{7}$ Osseous changes that are suggestive of TMD include, but are not limited to, surface erosion, sclerosis, and osteophyte formation. ${ }^{8,9}$ Various imaging techniques have been used such as tomography, arthrography, magnetic resonance imaging (MRI), and computed tomography (CT). ${ }^{7}$ Cone-beam computed tomography has relatively recently joined the armamentarium of TMJ imaging modalities. ${ }^{10}$ This three-dimensional (3D) imaging technique inherently eliminates superimposition and it also eliminates distortion and produces imaging results with high spatial resolution. ${ }^{11-13}$ Other advantages of CBCT include relatively shorter scan times and comparatively lower radiation doses when the appropriate imaging parameters are used. The aim of the current study was to correlate the clinical symptoms that are associated with TMD to the osseous changes occurring in the affected TMJ, as detected by CBCT. 


\section{Materials and Methods}

After ethics approval was obtained, the records for all patients who had presented to the oral and maxillofacial surgery (OMFS) department at an academic institution with symptoms related to the TMJ over a 1-year period were reviewed. Inclusion criteria included the presence of one or more clinical symptom and the presence of a $\mathrm{CBCT}$ examination. Exclusion criteria included clicking as the only symptom, lack of CBCT imaging, presence of neoplastic diseases, congenital anomalies, and/or traumatic injuries.

The data collected included the patients' age and gender, clinical findings such as pain (as measured on a 5-level visual analog scale), presence of joint sounds including clicking, presence of jaw deviation, frequency of locking if present, and MO measured in centimeters at the time of the initial presentation.

Because all patients in this study underwent their CBCT examination at the oral and maxillofacial radiology (OMFR) department of the same academic institution, the examination protocol was consistent for all the patients. All patients underwent imaging in the iCAT Classic CBCT unit (Imaging Sciences International, Hatfield, PA, USA), according to the manufacturer's recommendations, and using the following parameters: $16 \times 10 \mathrm{~cm}$ field-of-view (FOV) and $0.2 \mathrm{~mm}$ voxel size (VOX) with the patient in the closed-mouth position. Then, each patient was scanned again in the open-mouth position using a lower resolution ( $0.4 \mathrm{~mm}$ VOX).

The imaging reports, which are prepared by oral and maxillofacial radiologists, were evaluated for ten osseous findings considered to be the hallmarks of degenerative disease of the TMJ. These osseous findings include loss of cortication, condylar flattening, articular eminence (AE) flattening, joint space narrowing or widening, surface erosion, osteophyte formation, sclerosis, subchondral erosions, and the presence of joint mice.

Data analysis was performed using the "JAMOVI" and "JASP" statistical software. Some data were plotted using "QtiPlot". The Pearson Chi-square test and the McNemar test were used to analyze the data as appropriate. The logistic regression model was used to assess the incidence of age and gender in TMJ disorders, and their correlation with clinical and imaging findings. Further assessment of the correlation between clinical and imaging findings was performed. A conventional $p$ value $<0.05$ was the null hypothesis rejection criteria.

\section{Results}

Sixty patients were included in this study (120 TMJs because both joints were imaged). The mean age was 27.6 years. Our sample contained more female $(46,76.7 \%)$ than male $(14,23.3 \%)$ patients. However, there was no statistically significant difference in age distribution between the male (30.1 years) and female (26.8 years) patients $(p=0.094)$. The clinical findings are presented in Table 1.

A significant negative correlation was also found between pain and $\mathrm{MO}<4$ (Spearman's $\rho=-0.36 ; p<0.001$ ), while a significant positive correlation was found between $p$ and MO $<3$ (Spearman's $\rho=0.55 ; p<0.001)$. These results are shown in Figures 1 to 3 , respectively.

The frequency and the binomial distribution for the ten imaging parameters are summarized in Table 2 . Figure 4 shows a case of severe osseous changes in the right TMJ.

Binomial logistic regression of all the studied imaging findings with the gender revealed that only the subchondral erosion was correlated with gender (Table 3 ). The regression line with the model's confidence interval is shown in Figures 5 to 8 .
Binomial logistic regression also revealed that the only significantly correlated imaging findings with age were condylar flattening, narrow joint space and osteophyte formation (Figs 5 to 8 ).

There were no significant correlations between pain and any of the examined imaging parameters except for the loss of cortication where there was a positive significant correlation $(R=0.22, p=$ 0.046). This finding revealed that as the degree of cortication loss increased, the pain perception also increases (Table 4 and Figs 9 to 11). No significant correlations were recorded between deviation and any of the examined imaging parameters.

The model coefficient for age, osteophyte, $\mathrm{MO}<3 \mathrm{~cm}$, and $\mathrm{MO}<4 \mathrm{~cm}$ are presented in Figures 9 to 11 .

Clicking was negatively correlated with the following imaging findings: $\mathrm{AE}$ flattening $(p=0.009)$, wide joint space $(p=0.048)$, erosion $(p=0.046)$ and sclerosis $(p=0.042)$. These results are illustrated in Table 5 and the regression lines are illustrated in Figure 12.

\section{Discussion}

The average age of patients in this study was consistent with other published studies. ${ }^{14,15}$ Females comprised the majority of patients in the current study as it did in previously published studies. ${ }^{14,16}$ This can be attributed to several factors including anatomical,

Table 1: Frequency of the clinical findings for the 60 patients (120 temporomandibular joint)

\begin{tabular}{llll}
\hline Clinical finding & Right TMJ & Left TMJ & Total TMJ \\
\hline Pain & 44 & 34 & 78 \\
Joint sounds (clicking) & 38 & 24 & 62 \\
$\begin{array}{l}\text { Mandibular deviation with } \\
\text { locking }\end{array}$ & 14 & 4 & 18 \\
$\begin{array}{l}\text { Mandibular deviation without } \\
\text { locking }\end{array}$ & 6 & 14 & 20 \\
Mouth opening $>3 \mathrm{~cm}$ & & & \\
& & & $\begin{array}{l}(63.3 \%) \\
\text { Mouth opening }<3 \mathrm{~cm}\end{array}$ \\
\end{tabular}

TMJ, temporomandibular joint

Correlation between age and pain revealed a significant negative correlation (Spearman's $\rho=-0.23 ; p=0.01$; Fig. 1).

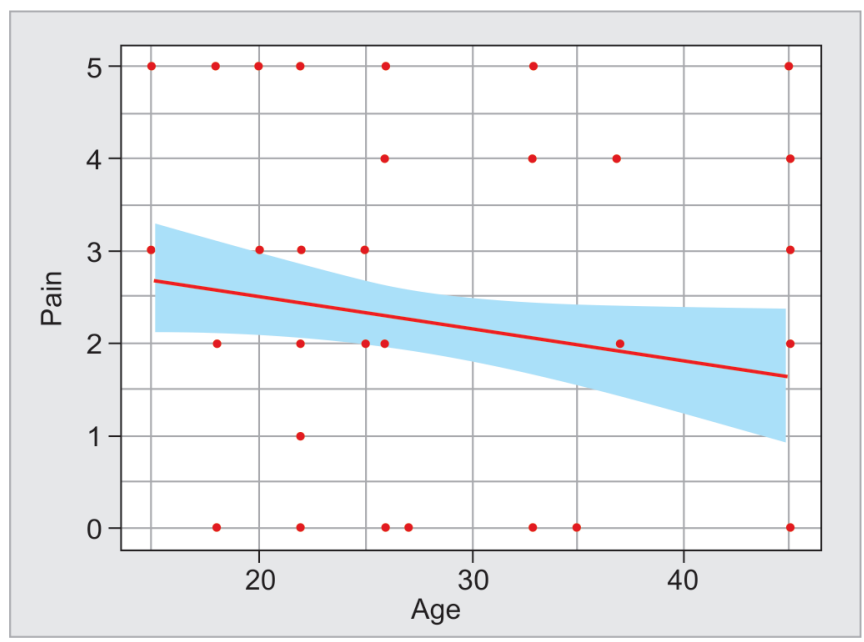

Fig. 1: Correlation and regression line of pain vs age 


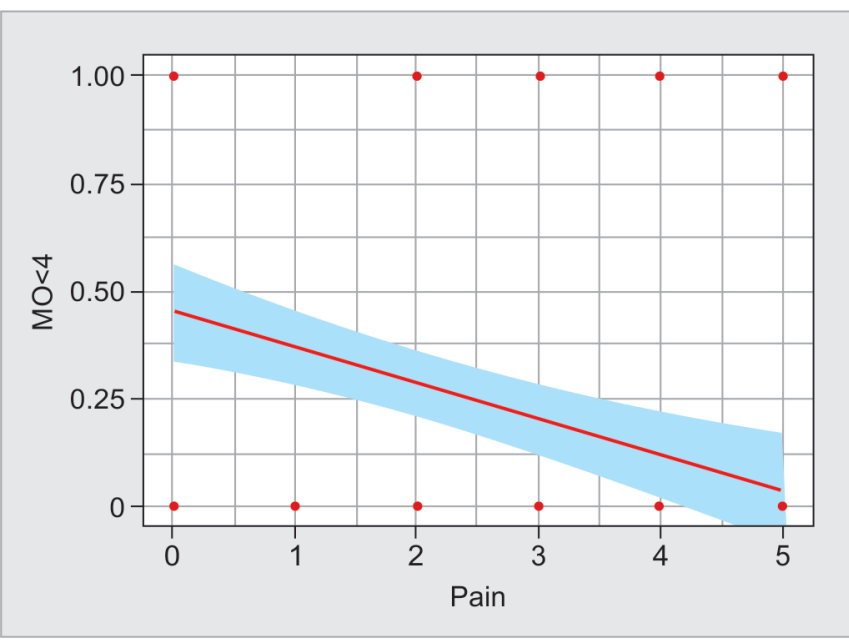

Fig. 2: Correlation and regression line of pain vs mouth opening $<4 \mathrm{~cm}$

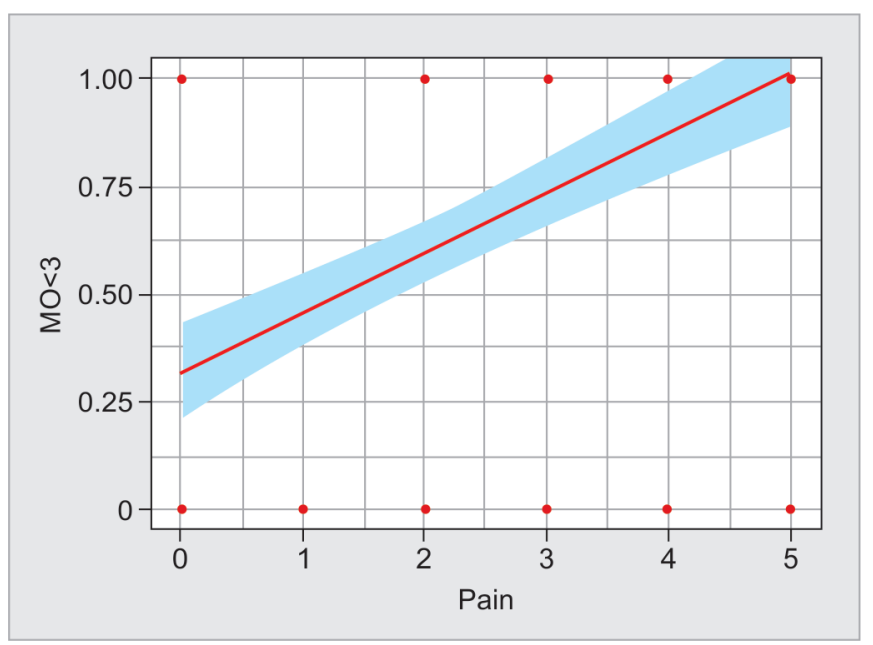

Fig. 3: Correlation and regression line of pain vs mouth opening $<3 \mathrm{~cm}$

Table 2: Distribution and binominal tests for the 10 imaging parameters

\begin{tabular}{|c|c|c|c|c|c|}
\hline Predictor & Level & Count & Total & Proportion & $p$ value \\
\hline \multirow[t]{2}{*}{ Loss of cortication } & 0 & 116 & 120 & 0.967 & $<0.001$ \\
\hline & 1 & 4 & 120 & 0.033 & $<0.001$ \\
\hline \multirow[t]{2}{*}{ Condylar flattening } & 0 & 56 & 120 & 0.467 & 0.523 \\
\hline & 1 & 64 & 120 & 0.533 & 0.523 \\
\hline \multirow[t]{2}{*}{ AE flattening } & 0 & 80 & 120 & 0.667 & $<0.001$ \\
\hline & 1 & 40 & 120 & 0.333 & $<0.001$ \\
\hline \multirow[t]{2}{*}{ NJS $(<3 \mathrm{~cm})$} & 0 & 96 & 120 & 0.800 & $<0.001$ \\
\hline & 1 & 24 & 120 & 0.200 & $<0.001$ \\
\hline \multirow[t]{2}{*}{ WJS $(>3 \mathrm{~cm})$} & 0 & 108 & 120 & 0.900 & $<0.001$ \\
\hline & 1 & 12 & 120 & 0.100 & $<0.001$ \\
\hline \multirow[t]{2}{*}{ Erosion } & 0 & 96 & 120 & 0.800 & $<0.001$ \\
\hline & 1 & 24 & 120 & 0.200 & $<0.001$ \\
\hline \multirow[t]{2}{*}{ Osteophyte } & 0 & 52 & 120 & 0.433 & 0.171 \\
\hline & 1 & 68 & 120 & 0.567 & 0.171 \\
\hline \multirow[t]{2}{*}{ Sclerosis } & 0 & 88 & 120 & 0.733 & $<0.001$ \\
\hline & 1 & 32 & 120 & 0.267 & $<0.001$ \\
\hline \multirow[t]{2}{*}{ Subchondral erosion } & 0 & 80 & 120 & 0.667 & $<0.001$ \\
\hline & 1 & 40 & 120 & 0.333 & $<0.001$ \\
\hline \multirow[t]{2}{*}{ Joint mice } & 0 & 116 & 120 & 0.967 & $<0.001$ \\
\hline & 1 & 4 & 120 & 0.033 & $<0.001$ \\
\hline
\end{tabular}

Note: $\mathrm{H}_{\mathrm{a}}$ is a proportion $\neq 0.5,0=$ absent, $1=$ positive

AE flattening, articular eminence flattening; NJS, narrow joint space (1.7-2 mm); WJS, wide joint space (>2 mm)

biological, and hormonal variations between males and females, as suggested by Bagis et al. ${ }^{17}$

Pain was significantly negatively correlated with age, and we hypothesize that this may be related to the adaptability of older patients to pain. Pain and clicking were significantly more severe in the right TMJ, and showed a positive correlation. This result is consistent with the findings of Di Paolo et al. where different TMJ clicking sounds were recorded and related to the occurrence of pain. ${ }^{15}$ Pain and clicking were manifested more in females and this can be interpreted based on Okuda et al. and Verma et al. findings, both of whom suggested that estrogen and prolactin hormones enhance articular bone and cartilage degradation either unilaterally or bilaterally. ${ }^{14,18} \mathrm{~A}$ significantly positive correlation was found between limited $\mathrm{MO}$ and pain, which is in agreement with previous work. ${ }^{14-16}$ This could be the result of a reciprocal action because painful jaw movements lead to direct reduction of MO and jaw movements.

The most common imaging findings were osteophyte in 68 patients $(56.6 \%)$, condylar flattening in 64 patients (53.3\%), AE flattening and subchondral erosion in 40 patients (33.3\%), sclerosis in 32 patients $(26.6 \%)$, NJS $(1.7-2 \mathrm{~mm})$ and erosion in 24 patients (20\%), WJS (>2 mm) in 12 patients (10\%), and loss of cortication and joint mice in four patients (3.3\%). The present findings are consistent with published results because Verma et al. reported flattening (66.7\%) followed by osteophyte (45\%), sclerosis (41.67\%) and erosion (35\%). ${ }^{14}$ However, subchondral erosion was the least recorded sign 


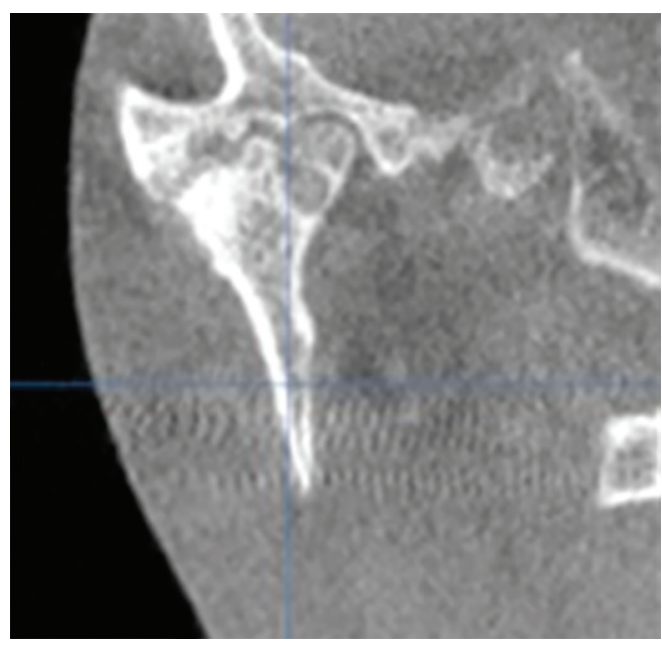

Fig. 4: Reconstructed cone-beam computed tomography image in the coronal plan of a right temporomandibular joint demonstrating severe osseous changes including erosions along the superior condylar head and mandibular fossa, osteophyte formation along the lateral aspect of the mandibular fossa, and subchondral sclerosis of the condylar head

Table 3: Model coefficient of logistic regression of subchondral erosion with gender

\begin{tabular}{llllll}
\hline Predictor & Estimate & $S E$ & $Z$ & $p$ & Odds ratio \\
\hline Intercept & -0.847 & 0.244 & -3.47 & $<0.001$ & 0.429 \\
$\begin{array}{l}\text { Subchondral } \\
\text { erosion }\end{array}$ & -1.350 & 0.581 & -2.32 & $0 / 020$ & 0.259 \\
\hline
\end{tabular}

Note: Estimate represents the log odds of "Gender $=\mathrm{M}$ " vs "Gender $=\mathrm{F}$ "

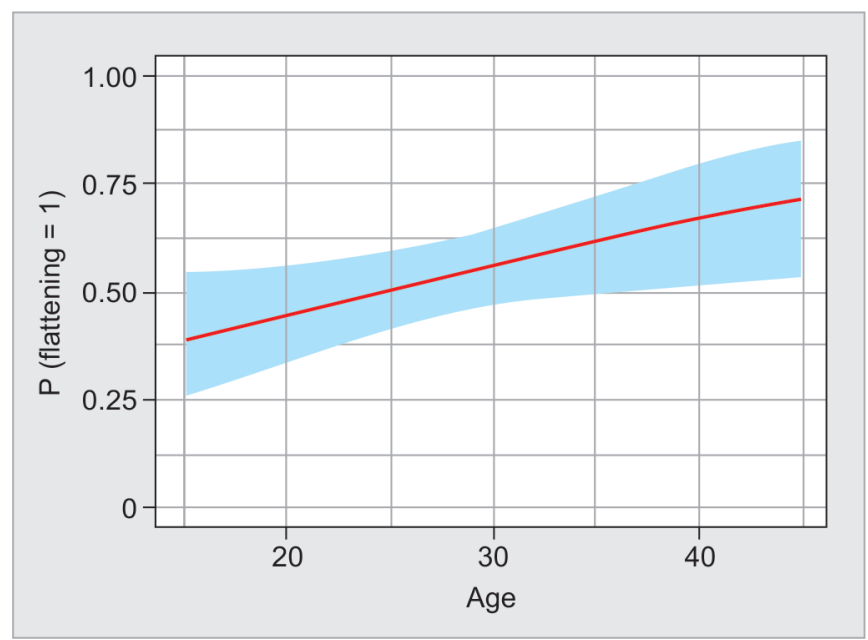

Fig. 6: Regression line with confidence interval for condylar flattening and age

(10\%). The present results are in general agreement with Shahidi et al., who found the most frequent findings to be flattening $(73.3 \%)$ and osteophyte (43.3\%). ${ }^{16}$ While Alkhader et al. recorded $14 \%$ for osteophyte formation among their patients with TMD. ${ }^{19}$ Edwards et al., however, explained that although erosions and osteophytes represent active degeneration, flattening and sclerosis are a state of physiologic remodeling. ${ }^{20}$ Further comparable results were related to reduced joint space because in the present study, reduced joint

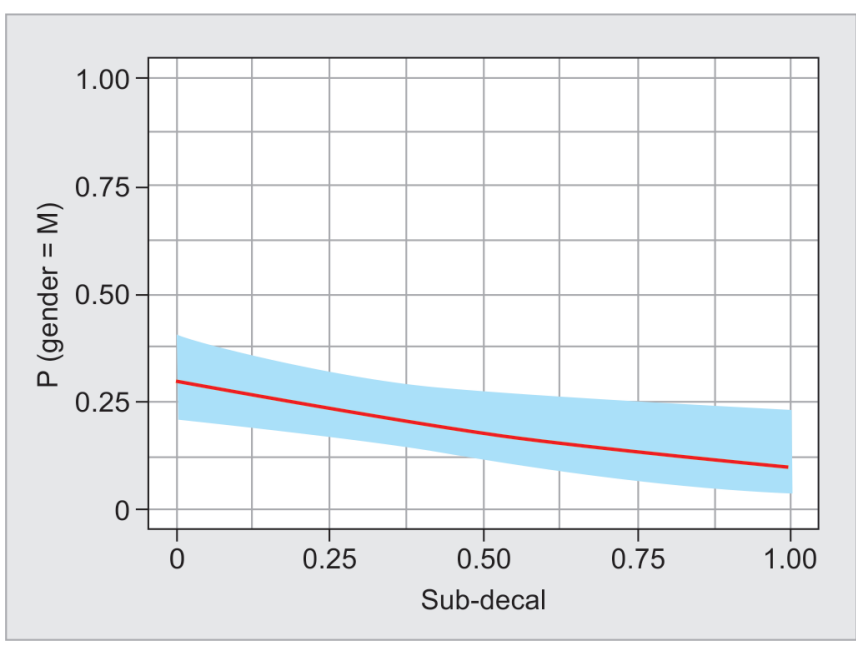

Fig. 5: Regression line with confidence interval for subchondral erosion vs gender

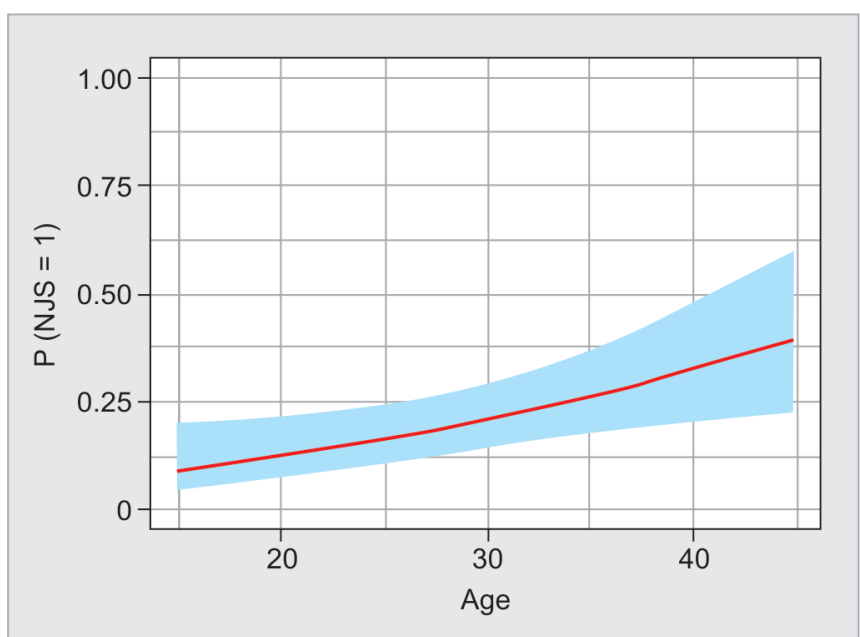

Fig. 7: Regression line with confidence interval for narrow joint space (NJS) and age

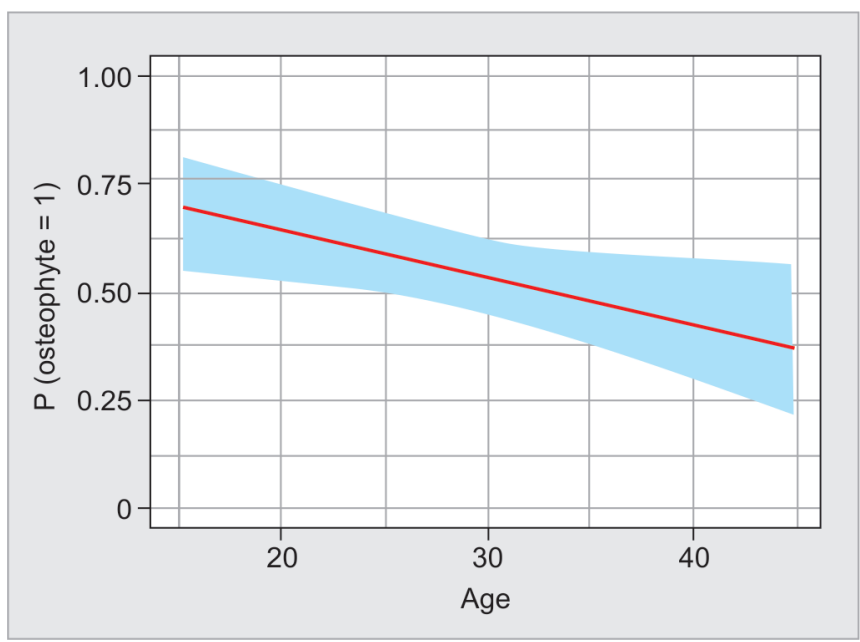

Fig. 8: Regression line with confidence interval for osteophyte formation and age 
Table 4: Model coefficient for the regression of pain with various imaging parameters

\begin{tabular}{lrlrr}
\hline Predictor & Estimate & \multicolumn{1}{l}{ SE } & \multicolumn{1}{l}{$t$} & \multicolumn{1}{l}{$p$} \\
\hline Intercept & 2.5470 & 0.361 & 7.059 & $<0.001$ \\
$\begin{array}{l}\text { Loss of corti- } \\
\text { cation }\end{array}$ & -2.2455 & 1.092 & -2.056 & 0.042 \\
$\begin{array}{l}\text { Condylar } \\
\text { flattening }\end{array}$ & -0.1695 & 0.424 & -0.399 & 0.690 \\
AE flattening & 0.2997 & 0.443 & 0.676 & 0.500 \\
NJS & 0.4352 & 0.665 & 0.654 & 0.514 \\
WJS & 0.5226 & 0.689 & 0.758 & 0.450 \\
Erosion & -0.7072 & 0.612 & -1.155 & 0.251 \\
Osteophyte & -0.2546 & 0.429 & -0.594 & 0.554 \\
Sclerosis & -0.0983 & 0.425 & -0.231 & 0.818 \\
Subchondral & -0.1771 & 0.448 & -0.395 & 0.693 \\
erosion & & & &
\end{tabular}

AE flattening, articular eminence flattening; NJS, narrowed joint space; WJS, widened joint space

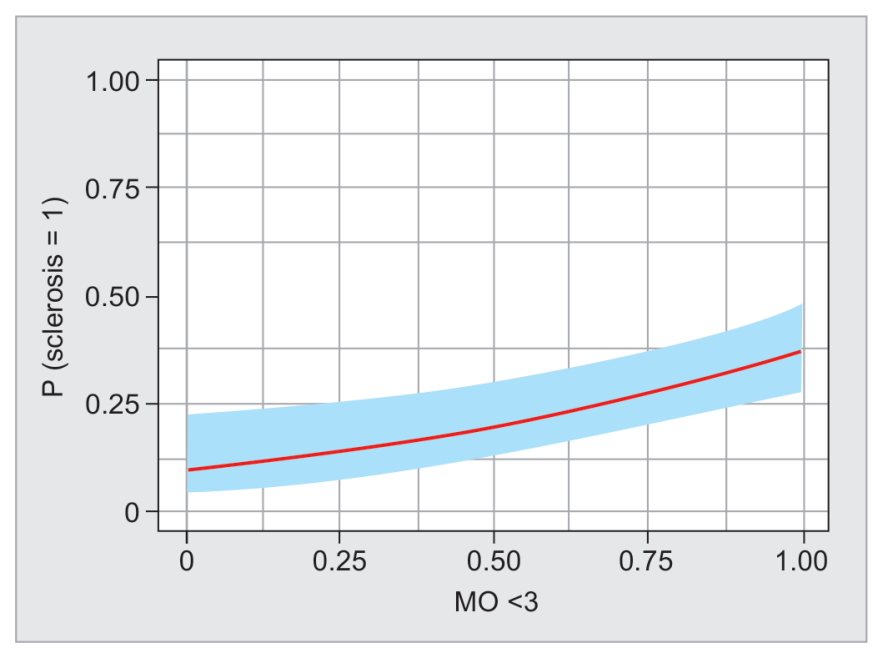

Fig. 10: Regression line with confidence interval for sclerosis with $\mathrm{MO}<3 \mathrm{~cm}$

space was observed in $20 \%$ of patients, while the results of Alexiou et al. and Shahidi et al. constituted $25 \%$ of examined TMJs. ${ }^{16,21}$

These interpretations may explain the present significant clinical correlation between age with condylar flattening, osteophyte, and narrow spaces. There was no significant correlation in this study between other clinical symptoms and further imaging evidence of degenerative bone disease, except for pain and loss of cortication. This is in agreement with previous findings. Based on the present results and previously published results, we can conclude that TMJ is subject to constant function leading to continuous wear and tear, and thus, the absence of an association between pain to imaging findings depicts the effect of the previous remodeling process rather than an acute degeneration process. ${ }^{10,14,16,22}$

\section{Conclusion}

Cone-beam computed tomography accurately assesses evident bony changes that are related to symptomatic TMJ. However, no significant correlation was found between evident degenerative

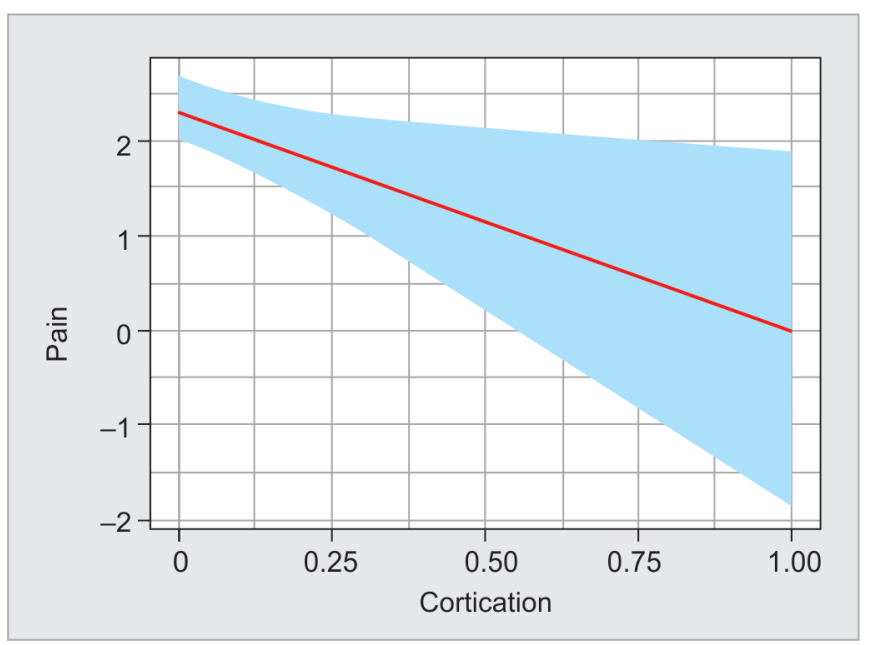

Fig. 9: Regression line with confidence interval for pain with loss of cortication

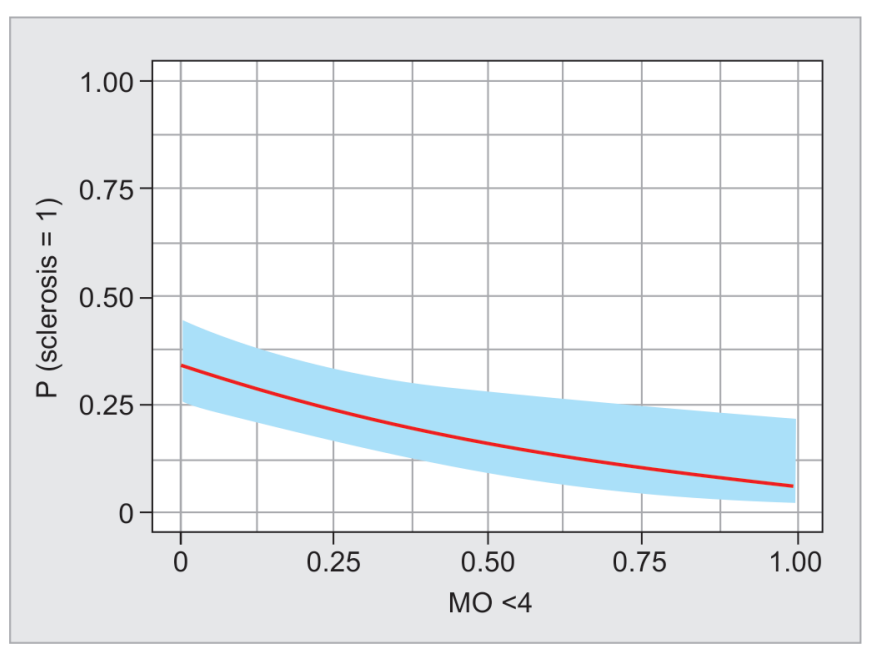

Fig. 11: Regression line with confidence interval for sclerosis with $\mathrm{MO}<4 \mathrm{~cm}$

Table 5: Model coefficient for clicking with various imaging parameters

\begin{tabular}{|c|c|c|c|c|}
\hline Predictor & Estimate & $S E$ & $t$ & $p$ value \\
\hline Intercept & 0.507 & 0.393 & 1.2901 & 0.197 \\
\hline $\begin{array}{l}\text { Loss of } \\
\text { cortication }\end{array}$ & 16.510 & 1199.772 & 0.0138 & 0.989 \\
\hline $\begin{array}{l}\text { Condylar } \\
\text { flattening }\end{array}$ & 0.676 & 0.498 & 1.3568 & 0.175 \\
\hline AE flattening & -1.440 & 0.550 & -2.621 & 0.009 \\
\hline NJS & 1.361 & 0.916 & 1.4860 & 0.514 \\
\hline WJS & 0.5226 & 0.689 & 0.758 & 0.137 \\
\hline Erosion & -1.727 & 0.865 & -1.9969 & 0.046 \\
\hline Osteophyte & -0.100 & 0.501 & -0.2004 & 0.841 \\
\hline Sclerosis & -1.058 & 0.520 & -2.0362 & 0.042 \\
\hline $\begin{array}{l}\text { Subchondral } \\
\text { erosion }\end{array}$ & -0.414 & 0.540 & -0.7660 & 0.444 \\
\hline Joint mice & -0.100 & 0.501 & -0.2004 & 0.841 \\
\hline
\end{tabular}

AE flattening, articular eminence flattening; NJS, narrowed joint space; WJS, widened joint space 

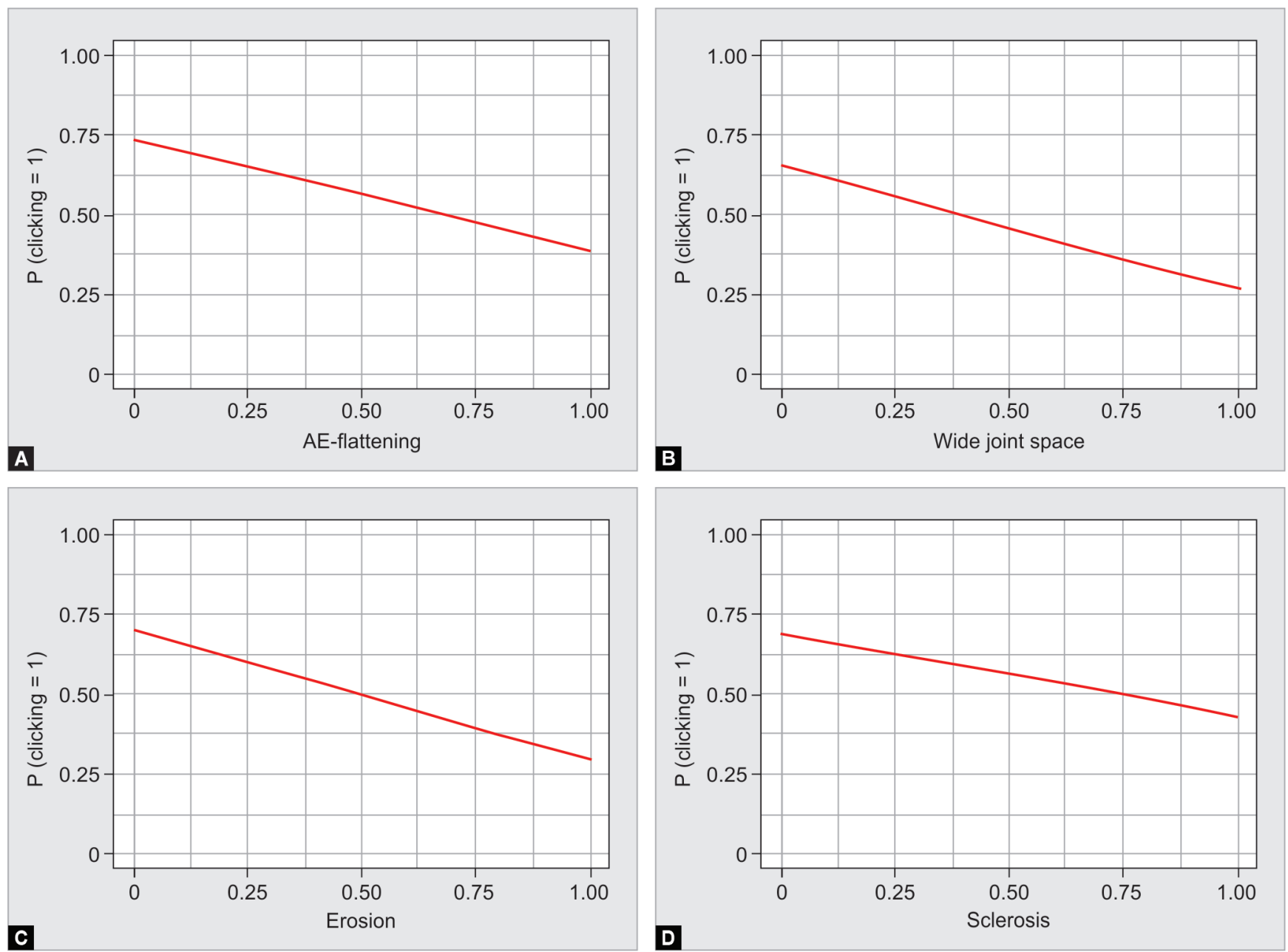

Figs $12 \mathrm{~A}$ to D: Regression lines for clicking and articular eminence flattening, wide joint space, erosion and sclerosis

changes and clinical symptoms. Thus, CBCT evaluation is important for providing information about the state of degeneration and remodeling and the level of degeneration regardless of the clinical manifestations. Additionally, clinical symptoms should be the most important factor to take into consideration when managing degenerative TMJ.

\section{References}

1. Fryback DG, Thornbury JR. The efficacy of diagnostic imaging. Med Decis Mak 1991;11(2):88-94. DOI: 10.1177/0272989X9101100203.

2. Dworkin SF, LeResche L. Research diagnostic criteria for temporomandibular disorders: review, criteria, examinations and specifications, critique. J Craniomandib Disord 1992;6(4):301-355.

3. Rollman GB, Gillespie JM. The role of psychosocial factors in temporomandibular disorders. Curr Rev Pain 2000;4(1):71-81. DOI: 10.1007/s11916-000-0012-8.

4. Barghan S, Merrill R, Tetradis S. Cone beam computed tomography imaging in the evaluation of the temporomandibular joint. Tex Dent $J$ 2012;129(3):289-302.

5. Milam SB, Schmitz JP. Molecular biology of temporomandibular joint disorders: proposed mechanisms of disease. J Oral Maxillofac Surg 1995;53(12):1448-1454. DOI: 10.1016/0278-2391(95)90675-4.

6. Palconet G, Ludlow JB, Tyndall DA, et al. Correlating cone beam CT results with temporomandibular joint pain of osteoarthritic origin. Dent Maxillofac Radiol 2012;41(2):126-130. DOI: 10.1259/ dmfr/60489374.
7. Tsiklakis K, Syriopoulos K, Stamatakis HC. Radiographic examination of the temporomandibular joint using cone beam computed tomography. Dent Maxillofac Radiol 2004;33(3):196-201.DOI: 10.1259/ $\mathrm{dmfr} / 27403192$.

8. Tetradis S, Anstey P, Graff-Radford S. Cone beam computed tomography in the diagnosis of dental disease. J Calif Dent Assoc 2010;38(1):27-32.

9. Talaat W, Al Bayatti S, Al Kawas S. CBCT analysis of bony changes associated with temporomandibular disorders. Cranio 2016;34(2): 88-94. DOI: 10.1179/2151090315Y.0000000002.

10. Honda K, Larheim TA, Johannessen S, et al. Ortho cubic super-high resolution computed tomography: a new radiographic technique with application to the temporomandibular joint. Oral Surg Oral Med Oral Pathol Oral Radiol Endodont 2001;91(2):239-243. DOI: 10.1067/ moe.2001.111942.

11. Preda L, Di Maggio EM, Dore R, et al. Use of spiral computed tomography for multiplanar dental reconstruction. Dent Maxillofac Radiol 1997;26(6):327-331. DOI: 10.1038/sj.dmfr.4600290.

12. Mozzo P, Procacci C, Tacconi A, et al. A new volumetric CT machine for dental imaging based on the cone-beam technique: preliminary results. Eur Radiol 1998;8(9):1558-1564. DOI: 10.1007/s003300050586.

13. Cohnen M, Kemper J, Mobes $O$, et al. Radiation dose in dental radiology. Eur Radiol 2002;12(3):634-637. DOI: 10.1007/s003300100928.

14. Verma PSV, Kadam S, Umarji HR, et al. Assessment of joint space and arthritic changes in temporomandibular joint as visualized on cone beam computed tomography scan. Indian J Oral Med Radiol 2016;28(4):358-363. DOI: 10.4103/jiaomr.JIAOMR_34_16. 
15. Di Paolo C, Costanzo GD, Panti F, et al. Epidemiological analysis on 2375 patients with TMJ disorders: basic statistical aspects. Ann Stomatol (Roma) 2013;4(1):161-169. DOI: 10.11138/ads.0161.

16. Shahidi S, Salehi P, Abedi P, et al. Comparison of the bony changes of TMJ in patients with and without TMD complaints using CBCT. J Dent (Shiraz) 2018;19(2):142-149.

17. Bagis B, Ayaz EA, Turgut $S$, et al. Gender difference in prevalence of signs and symptoms of temporomandibular joint disorders: a retrospective study on 243 consecutive patients. Int J Med Sci 2012;9(7):539-544. DOI: 10.7150/ijms.4474.

18. Yasuoka T, Nakashima M, Okuda T, et al. Effect of estrogen replacement on temporomandibular joint remodeling in ovariectomized rats. J Oral Maxillofac Surg 2000;58(2):189-196. DOI: 10.1016/S02782391(00)90337-9.

19. Alkhader M, Ohbayashi N, Tetsumura A, et al. Diagnostic performance of magnetic resonance imaging for detecting osseous abnormalities of the temporomandibular joint and its correlation with cone beam computed tomography. Dent Maxillofac Radiol 2010;39(5):270-276. DOI: $10.1259 / \mathrm{dmfr} / 25151578$.

20. Edwards R, Alsufyani N, Heo G, et al. The frequency and nature of incidental findings in large-field cone beam computed tomography scans of an orthodontic sample. Prog Orthod 2014;15(1):37. DOI: 10.1186/s40510-014-0037-x.

21. Alexiou K, Stamatakis H, Tsiklakis K. Evaluation of the severity of temporomandibular joint osteoarthritic changes related to age using cone beam computed tomography. Dento Maxillofac Radiol 2009;38(3):141-147. DOI: 10.1259/dmfr/59263880.

22. Wiese $M$, Svensson $P$, Bakke $M$, et al. Association between temporomandibular joint symptoms, signs, and clinical diagnosis using the RDC/TMD and radiographic findings in temporomandibular joint tomograms. J Orofac Pain 2008;22(3):239-251. 